\title{
An Oculopharyngeal Subtype of Guillain-Barré Syndrome Sparing the Trochlear and Abducens Nerves
}

\author{
Masafumi Arakawa, Mineo Yamazaki, Yusuke Toda, Akiko Ozawa and Kazumi Kimura
}

\begin{abstract}
:
Guillain-Barré syndrome (GBS) comprises a group of polyneuropathies characterized by rapid progression of limb paralysis. Various subtypes of GBS have been reported. The oculopharyngeal subtype of GBS is currently understood to be primarily a cranial polyneuropathy without limb weakness or cerebellar ataxia. In our case of 62-year-old man, gastrointestinal infection was followed by paranesthesia of the hands. He had bilateral ptosis, pharyngeal disorder, and tongue and bifacial weakness. We diagnosed oculopharyngeal subtype of GBS. It responded to intravenous immunoglobulin. This case highlights the need for further characterization of unusual GBS subtypes.
\end{abstract}

Key words: Guillain-Barré syndrome, GBS, multiple cranial nerve palsy, oculopharyngeal subtype

(Intern Med 59: 1215-1217, 2020)

(DOI: 10.2169/internalmedicine.3395-19)

\section{Introduction}

Guillain-Barré syndrome (GBS) comprises a group of polyneuropathies characterized by rapid progression of limb paralysis. Various subtypes of GBS have been reported. Oculopharyngeal subtype of GBS is currently understood to be primarily a cranial polyneuropathy without limb weakness or cerebellar ataxia (1). Here, we present a case of GBS with multiple cranial nerve palsy following a gastrointestinal infection.

\section{Case Report}

A 62-year-old man noticed sensory disturbance in all fingers on both hands (day 1), two weeks after a 5-day history of diarrhea. A few days after the onset of the sensory symptom, he developed blepharoptosis, dysarthria, and dysphagia. His sensory symptom disappeared by day 9 , but the others persisted. Then he was admitted to our hospital on day 10 .

Neurological examination revealed bilateral blepharoptosis without ocular motility disorder, but with bilateral facial weakness, dysarthria, dysphagia, and tongue weakness. He had no pupillary abnormality and taste disorders. All other cranial nerves $(\mathrm{CN})$ were normal. There was neither muscle weakness in the limbs, nor any sensory disorder. All deep tendon reflexes were normal, and no pathological reflexes were revealed. There was no cerebellar ataxia, and other neurological examinations were normal.

A non-contrast brain magnetic resonance imaging (MRI) scan on day 18 and an MRI scan with gadolinium on day 25 showed no abnormalities. The edrophonium test was negative. Cerebrospinal fluid (CSF) analysis on admission demonstrated normal glucose level, cell count of $1 / \mu \mathrm{L}$, protein concentration of $40 \mathrm{mg} / \mathrm{dL}$ (normal range; $10-40 \mathrm{mg} /$ $\mathrm{dL}$ ), and negative cytological findings. Serological analysis showed negative results for potential viral infection (antibodies to herpes simplex virus 1 and 2, Varicella-zoster, cytomegalovirus, and Epstein-Barr). Serum analyses for antinuclear antibodies, anti-neutrophil cytoplasmic antibodies, anti-acetylcholine receptor antibody, and anti-muscle-specific kinase antibody were negative. The angiotensin-converting enzyme level was normal. Nerve conduction study (NCS) showed slight reduction in the amplitude of the sensory nerve action potential of the median and sural nerve. Moreover, we observed reduced conduction velocities in these two sensory nerves, whereas that of all other nerves were normal.

We tested for serum IgG and IgM antibodies to gangliosides (GM1, GM2, GM3, GD1a, GD1b, GD3, GT1b, 
Table. Clinical Features and Investigation.

\begin{tabular}{|c|c|c|c|c|c|c|c|}
\hline \multirow[t]{2}{*}{ Case } & \multirow[t]{2}{*}{ Reference } & \multirow[t]{2}{*}{ Age/gender } & \multirow[t]{2}{*}{$\mathrm{CN}$ examination related to eye movement } & \multicolumn{3}{|c|}{$\begin{array}{l}\text { Disorder of CN } \\
\text { III, IV, VI }\end{array}$} & \multirow{2}{*}{$\begin{array}{c}\text { Anti-GQ1b } \\
\text { antibody }\end{array}$} \\
\hline & & & & III & IV & VI & \\
\hline 1 & (5) & 20/M & Bilateral ptosis, Bilateral opthalmoplegia & & $\bigcirc$ & J & negative \\
\hline 2 & (6) & $67 / \mathrm{F}$ & Bilateral complete opthalmoplegia & & $\bigcirc$ & no & - \\
\hline 3 & (6) & $33 / \mathrm{M}$ & Bilateral median and lateral gaze limitation & & $\bigcirc$ & $\bigcirc$ & - \\
\hline 4 & (6) & $47 / \mathrm{M}$ & Bilateral upgaze and lateral gaze limitation & & no & $\bigcirc$ & positive \\
\hline 5 & (7) & $52 / \mathrm{M}$ & Bilateral upgaze and lateral gaze limitation & & no & $\bigcirc$ & positive \\
\hline 6 & (8) & 39/M & Right ptosis & & no & no & - \\
\hline 7 & (9) & $41 / \mathrm{F}$ & Bilateral ptosis, Bilateral complete opthalmoplegia & & $\bigcirc$ & $\bigcirc$ & - \\
\hline 8 & (10) & $36 / \mathrm{F}$ & Bilateral ptosis, Bilateral opthalmoplegia & & & $\bigcirc$ & - \\
\hline 9 & (11) & $83 / \mathrm{F}$ & Left ptosis, Left complete opthalmoplegia & & ) & ○ & - \\
\hline 10 & $(12)$ & $48 / \mathrm{M}$ & Bilateral ptosis, Bilateral complete opthalmoplegia & & $\bigcirc$ & $\bigcirc$ & - \\
\hline 11 & (13) & $48 / \mathrm{M}$ & Bilateral ptosis, Bilateral opthalmoplegia & & $\bigcirc$ & $\bigcirc$ & positive \\
\hline 12 & (14) & $54 / \mathrm{M}$ & Bilateral ptosis, Bilateral opthalmoplegia & & $\bigcirc$ & $\bigcirc$ & negative \\
\hline 13 & $(15)$ & $55 / \mathrm{M}$ & Left ptosis, Left complete opthalmoplegia & & no & no & - \\
\hline 14 & Our case & $62 / \mathrm{M}$ & Bilateral ptosis & & no & no & positive \\
\hline
\end{tabular}

$\mathrm{CN}$ : cranial nerve, $\mathrm{M}$ : male, $\mathrm{F}$ : female

GQ1b, galactocerebroside, and GalNAc-GD1a), and serum IgG to glycolipids GD1a/GD1b. IgG and IgM antibodies to GD1a, GT1b, and GQ1b were positive; all other antiglycolipid antibodies were negative.

We diagnosed GBS on the basis of the diagnostic criteria for the oculopharyngeal GBS subtype (1). On day 32, we started intravenous immunoglobulin (IVIG) therapy at $0.4 \mathrm{~g} /$ $\mathrm{kg} /$ day for 5 days. The patient showed considerable improvement of bilateral blepharoptosis after 3 days of therapy; after 2 weeks, his symptoms were reduced to mild facial weakness and dysphagia.

\section{Discussion}

Classically, Miller Fisher syndrome (MFS) and the pharyngeal-cervical-brachial (PCB) variant are reported as subtypes of GBS with cranial nerve palsy $(2,3)$. MFS is a clinical diagnosis based on the three characteristic symptoms of ophthalmoplegia, ataxia, and absence of the tendon reflexes. The PCB variant is defined by rapidly progressive oropharyngeal, cervical, and brachial weakness accompanied by upper limb areflexia. In our case, absence of the three definitive symptoms of extraocular muscle palsy, ataxia, and deep tendon reflex reduction meant that our patient was not categorized as MFS. His absence of neck muscle and upper limb muscle weakness also excluded the PCB variant.

Rapid progressive bifacial weakness categorized as bifacial weakness with paresthesia (BFP), occasionally presents in GBS subtypes (4). Although isolated CN VII palsy occurs in this subtype, no other $\mathrm{CN}$ is involved in its progression. In addition to bilateral facial paralysis due to the involvement of CN VII, our patient developed bilateral blepharoptosis involving CN III, and pharyngeal disorder and tongue weakness involving CN IX, X, and XII. Therefore, our case was not categorized as BFP.
Recently, polyneuritis cranialis was proposed as an oculopharyngeal subtype of $\operatorname{GBS}(1,5)$. In previously reported cases of this variant, CN I and CN II were spared; most cases showed progressive involvement of ocular (CN III, IV, and VI) and pharyngeal (CN IX, X, and XII) symptoms. Limb weakness and cerebellar ataxia were not present. Deep tendon reflexes and NCS of the limbs were not necessarily abnormal. Protein cell dissociation in cerebrospinal fluid may be observed. This subtype is occasionally positive for anti-GQ1b antibody $(6,7)$. The table summarizes the clinical features related to eye movements and the presence or absence of anti-GQ1b antibodies in some cases of oculopharyngeal subtype of GBS (5-15). Only two previous cases of CN III disorder without the involvement of both CN IV and VI have been reported. Serum anti-GQ1b antibodies were positive in three previous cases. GQ1b is located in the area of CN III, IV, and VI that dominates the extraocular muscle, which suggests that anti-GQ1b antibody is associated disorders of these CN (16).

Despite severe blepharoptosis, the extraocular and intraocular muscles were completely preserved in our case. Only a few cases of severe ptosis without ophthalmoplegia in patients with Guillain-Barre syndrome or polyneuropathy have been reported previously $(3,17)$. The oculomotor nucleus consists of different nerve nuclei, each of which innervates the extraocular muscles, intraocular muscles, and levator palpebrae superioris (18). The central caudal nucleus of the oculomotor nucleus innervates the levator palpebrae superioris. Hence, it was assumed that blepharoptosis without extra- and intraocular muscle paralysis was caused by selective dysfunction of the central caudal nucleus (19).

\section{Conclusion}

Although clinical variation in GBS has been well-studied, a few cases of GBS with multiple cranial paralysis have 
been reported. We present a case of polyneuritis cranialis GBS that highlights the necessity for further characterization of GBS subtypes.

The authors state that they have no Conflict of Interest (COI).

\section{Acknowledgement}

The authors would like to thank Prof. Susumu Kusunoki and his colleagues (Kindai University, Faculty of Medicine, Osaka, Japan) for quantification of anti-ganglioside antibodies.

\section{References}

1. Wakerley BR, Yuki N. Polyneuritis cranialis: oculopharyngeal subtype of Guillain-Barré syndrome. J Neurol 262: 2001-2012, 2015.

2. Fisher M. An unusual variant of acute idiopathic polyneuritis (syndrome of ophthalmoplegia, ataxia and areflexia. N Engl J Med 255: 57-65, 1956.

3. Ropper AH. Unusual clinical variants and signs in Guillain-Barré syndrome. Arch Neurol 43: 1150-1152, 1986.

4. Morgan C, Fuller G, Wakerley BR. Bifacial weakness with paresthesia: serial nerve conduction studies indicate diffuse demyelinating neuropathy. Muscle Nerve 53: 818-822, 2016.

5. Dosi R, Ambaliya A, Patel N, Shah M, Patell R. Acute multiple cranial neuropathy: an oculopharyngeal variant of Guillain-Barré syndrome. Australas Med J 7: 376-378, 2014.

6. Lyu RK, Chen ST. Acute multiple cranial neuropathy: a variant of Guillain-Barré syndrome? Muscle Nerve 30: 433-436, 2004.

7. Edvardsson B, Persson S. Polyneuritis cranialis presenting with anti-GQ1b IgG antibody. J Neurol Sci 281: 125-126, 2009.

8. Henderson R, Gilroy J, Huber P, Meyer JS. Landry-Guillain-Barré syndrome with cranial nerve involvement (polyneuritiscranialis).
Harper Hosp Bull 22: 59-62, 1964.

9. Banerji NK. Acute polyneuritis cranialis with total external ophthalmoplegia and areflexia. Ulster Med J 40: 14-16, 1971.

10. McFarland HR. Polyneuritis cranialis as the sole manifestation of the Guillain-Barré syndrome. Mo Med 73: 227-229, 1976.

11. Juncos JL, Beal MF. Idiopathic cranial polyneuropathy. A fifteenyear experience. Brain 110: 197-211, 1987.

12. Yamashita H, Koga M, Morimatsu M, Yuki N. Polyneuritis cranialis related to anti-GT1a IgG antibody. J Neurol 248: 65-66, 2001.

13. $\mathrm{Yu}$ JY, Jung $\mathrm{HY}$, Kim $\mathrm{CH}$, et al. Multiple cranial neuropathies without limb involvements: guillain-Barré syndrome variant? Ann Rehabil Med 37: 740-744, 2013.

14. Toro J, et al. Multiple cranial neuropathy (a teaching case). Multiple Scler Relat Disord 2: 395-398, 2013.

15. Ralapanawa U, et al. Guillain Barré syndrome with associated unilateral ptosis witout ophthalmoplegia-a rear presentation: a case report and review of the literature. J Med Case Rep 13: 221, 2019.

16. Susuki K, Yuki N, Hirata K. Fine specificity of anti-GQ1b $\operatorname{IgG}$ and clinical features. J Neurol Sci 185: 5-9, 2001.

17. Tan E, Kansu T, Zileli T. Severe ptosis without ophthalmoplegia due to porphyric neuropathy. Clin Neurol Neurosurg 92: 287-288, 1990.

18. Tsuda H, Tanaka K. Clinico-anatomical analysis of the fibers to the inferior rectus muscle in the oculomotor fascicles. Intern Med 51: 2031-2034, 2012.

19. Ropper AH. The CNS in Guillain-Barré syndrome. Arch Neurol 40: 397, 1983.

The Internal Medicine is an Open Access journal distributed under the Creative Commons Attribution-NonCommercial-NoDerivatives 4.0 International License. To view the details of this license, please visit (https://creativecommons.org/licenses/ by-nc-nd/4.0/).

(C) 2020 The Japanese Society of Internal Medicine Intern Med 59: 1215-1217, 2020 